\title{
A EDUCAÇÃO DO CABOCLO-RIBEIRINHO: PROBLEMATIZAÇÕES ACERCA DO CURRÍCULO ESCOLAR E SEUS DESDOBRAMENTOS NAS ESCOLAS RIBEIRINHAS
}

\author{
Francisco Miguel da Silva de Oliveira ${ }^{1}$, Alex Sandro Gomes Pessoa ${ }^{2}$ \\ ${ }^{1}$ Mestre em Educação pela Universidade do Oeste Paulista - UNOESTE, Presidente Prudente, SP. Docente de filosofia \\ no Sistema de Organização Modular de Ensino (SOME) pela Secretaria de Estado de Educação (SEDUC/PA). \\ ${ }^{2}$ Doutor em Educação pela Universidade Estadual Paulista - UNESP. Docente do Departamento de Psicologia da \\ Universidade Federal de São Carlos - UFSCar.E-mail: alexpessoa@ufscar.br
}

\section{RESUMO}

Este artigo se configura como um ensaio teórico sobre a temática do currículo e seus desdobramentos na realidade de escolas ribeirinhas. Visa, em primeira instância, elucidar questões conceituais sobre currículo e apontar os descompassos entre conteúdos escolares que são definidos arbitrariamente e se tornam descontextualizados para a realidade educacional das instituições em questão. Em seguida, são trazidos elementos que caracterizam a realidade das escolas ribeirinhas, visando ilustrar este contexto ao leitor e apresentar parte dos aspectos sociais que circundam estes espaços. Argumenta-se que os currículos escolares não dialogam com a realidade das comunidades ribeirinhas, o que se desdobra em ações educativas inócuas, esvaziadas de sentido e distantes de transformações sociais profundas.

Palavra-chave: Educação. Currículo. Escolas Ribeirinhas.

\section{DISCUSSIONS ON THE SCHOOL CURRICULUM AND ITS REPERCUSSIONS IN THE RIVERSIDE SCHOOLS REALITY}

\begin{abstract}
This article consists as a theoretical essay on the thematic of curriculum and its unfolding in the reality of riverside schools. In the first instance, it aims to elucidate conceptual issues about curriculum and points out the mismatches between school contents that are defined arbitrarily and become decontextualized for the educational reality of the riverside schools. Then, some social aspects are brought in regarding the riverside schools, aiming to characterize this reality to the reader, as well as to present some of the social aspects that surround this context. It is argued that school curricula do not dialogue with the reality of the riverside communities, resulting in innocuous educational actions, devoid of meaning and distant of deep social transformations.
\end{abstract}

Keywords: Education. Curriculum. Riverside School.

\section{INTRODUÇÃO}

Este artigo se configura como um ensaio teórico sobre a temática de currículo e seus desdobramentos na realidade de escolas ribeirinhas. Visa, em primeira instância, elucidar questões conceituais sobre currículo e apontar os descompassos entre conteúdos acadêmicos definidos arbitrariamente e que se tornam descontextualizados para a realidade educacional das instituições em questão.

As discussões sobre o currículo, de longa data, têm provocado calorosos debates no meio escolar. Pesquisadores têm dedicado esforços no sentido de desvencilhar indagações que pairam sobre o campo curricular. Sabe-se que as propostas curriculares vigentes são decorrentes de interesses particulares e estão ligadas a interesses de determinados grupos sociais que almejam a manutenção de determinada ordem social (ARROYO; 2011; OLIVEIRA; 2007; APPLE, 2006).

A verticalização curricular na educação convoca pesquisadores a desenvolver estudos que melhor caracterizem essa realidade. Parte-se da ideia que uma proposta pedagógica deve estar alinhada a fatores sociais relevantes 
contextualmente para o desenvolvimento de uma educação de qualidade. Sem dúvida, tal princípio exige a elaboração de um currículo escolar contextualizado e que dialogue com as experiências vividas pela população que está inserida em determinado contexto social.

Compreende-se que essa articulação dignifica a educação, ancorando-a ao processo democrático de acesso ao conhecimento científico. É salutar que a discussão sobre currículo tenha uma relação visceral com alguns aspectos intrínsecos à vida e condição humana. Tempo e espaço onde se vive são elementos essenciais, pois as construções históricas e culturais fazem surgir valores, costumes, hábitos, atividades de trabalho e, certamente, deveriam balizar, também, a construção do currículo.

Neste ensaio, apresenta-se, incialmente, conceitos de currículo, no sentido de oferecer uma contribuição epistêmica que seja relevante para a problemática central. Busca-se, com isso, potencializar as análises sobre determinados aspectos sociais que carecem de atenção quando se propõe uma educação escolar que compreende o ser humano dentro do seu processo de formação histórico e ontológico. Em seguida, pretende-se abordar como o currículo formal trabalhado nas escolas não tem compreendido as peculiaridades das comunidades ribeirinhas. $\mathrm{O}$ argumento central é que a escola é um espaço de lutas ideológicas e que o currículo pode ser muitas vezes, um instrumento a serviço de práticas de dominação e adestramento das comunidades ribeirinhas.

\section{CURRÍCULO ESCOLAR E CONTEXTO SOCIAL: DEBATES NECESSÁRIOS PARA O CAMPO EDUCACIONAL}

Para discutir com profundidade o currículo escolar, torna-se necessário questionar diversos fatores que influenciam sistematicamente a forma de organização do espaço escolar. É relevante, nesse sentido, indagar o modelo de educação atual, ou seja, questionar a forma como a escola tem conduzido suas atividades pedagógicas, bem como 0 contexto social em que está inserida e quais suas peculiaridades.

Silva (1999, p.46) afirma que "currículo é o resultado de um processo que reflete os interesses particulares das classes dominantes". Arroyo (2011, p. 13), por sua vez, destaca que o currículo "é o território mais cercado, mais normatizado", mas também pode ser o mais politizado, inovado e ressignificado. Estas considerações expressam que existe um jogo de interesse envolvendo o currículo, na medida em que manifesta a vontade de determinados grupos sociais. O poder e a dominação, pode se dizer, são elementos presentes nas propostas curriculares, pois pode representar imposição dos interesses de uma classe social à outra. Freire (2005) alerta que a prescrição representa a imposição de uma consciência dominante que realça a condição ideológica que perpassa o currículo.

O estudo de Macedo (2011, p.22) apresenta a etimologia do lexema currículo: "proveniente do étimo latino currere, significa caminho, jornada, trajetória, percurso a seguir". $\mathrm{O}$ autor oferece um conceito instigante, pois expressa que o currículo é o instrumento para a formação humana. Todavia, como já explicitado, as ideologias e intensões nele presentes definem o ser humano que se pretende formar.

Por esta razão, entende-se currículo como elemento emblemático no processo de formação humana. Assim, é fundamental atentar para aspectos que identificam a função do currículo escolar. Para Abreu (2013), o currículo pode se estabelecer como um "monólogo", caracterizado eminentemente pela prescrição, ou seja, conteúdo em forma de receituário que não tem articulação com os aspectos da vida social do sujeito. Todavia, a escola, defende o autor, deve ser o espaço que estimule à pergunta, à crítica e, certamente, a construção coletiva do conhecimento (ABREU, 2013, p. 101).

A elaboração do currículo escolar está intimamente ligada a fatores históricos, ideológicos, de poder e de construção de saberes que influenciam no processo de formação do ser humano. É necessário investigar toda a dinâmica de embates que envolvem o campo curricular para que se possa desmistificar vontades e ideologias que maculam a maneira como os saberes sociais são tratados.

O currículo que ignora as experiências sociais dos sujeitos de uma determinada comunidade está comprometido com uma educação adestradora. Nesse sentido, Freire (2005) destaca que o oprimido passa a ter uma "consciência servil", de um "ser para o outro". o oprimido passa a ser hospedeiro do opressor, na medida em que seu agir e pensar estão condicionados exatamente ao que deseja o opressor. Esse debate é, sem dúvida, necessário para que se consiga refletir, de forma 
contundente, sobre a temática do currículo escolar. É importante atentar que quando se desconsidera a maneira como as relações são estabelecidas dentro de um espaço social e não se observa atentamente a cultura e a história dos envolvidos no processo de construção do conhecimento, têm-se os elementos necessários para que se prospere uma educação que esteja alinhada com os anseios de grupos que detêm a hegemonia.

Analisar o currículo escolar é uma forma de conhecer mais detalhadamente a realidade escolar. Por esta razão, se compreende o currículo como elemento central do Projeto Político Pedagógico (PPP), pois mantêm uma ligação intrínseca com o desenvolvimento do processo de ensino e aprendizagem a partir da realidade social. Segundo Jesus (2008), o currículo é o elo entre o contexto social que circunda a escola e a prática pedagógica desenvolvida pela mesma. Na mesma direção, Oliveira (2008) pontua que o currículo é uma elaboração coletiva que se efetiva diariamente no convívio social.

É por essa razão que se afirma que o currículo é fator emblemático no processo de construção do conhecimento. Ele deve dialogar com as demandas presentes nas relações estabelecidas socialmente e as peculiaridades devem ser observadas para compor a proposta curricular. Assim, compreende-se que currículo não pode representar prescrição, tampouco, imposição. Antes, deve apontar para o desenvolvimento de uma postura crítica e reflexiva da comunidade escolar sobre o modo de viver de uma sociedade.

Como já apresentado, é notório que o currículo pode servir como um instrumento de controle social. Sabe-se, nesse campo de embates, que a educação escolar tem se preocupado, majoritariamente, em preparar o indivíduo para o mundo do trabalho dentro de uma lógica imposta pelo capital. A formação para a vida social, baseada em valores éticos e morais, tem sido relegada a segundo plano (MEZSÁROS, 2011). É preciso que a escola tenha o propósito de investigar e questionar os saberes mediados em seu espaço.

A sugestão de Mozatto (2013) é que a escola se aproprie do princípio da "racionalidade comunicativa", utilizando a intersubjetividade como fala e o modo de vida do sujeito que possibilita a interação entre os sujeitos de uma realidade. A racionalidade comunicativa está embasada pelo diálogo como princípio norteador de suas ações. A escola deve dialogar com as pessoas, com o conhecimento e com o contexto onde está presente para se transformar num espaço de formação efetiva. Mozatto (2013) acrescenta, ainda, que a escola não deve utilizar como princípio a "racionalidade unilateral", pois esta transforma a educação em um processo estático, sem dinamismo e descontextualizada.

\section{ENTRE RIOS E FLORESTAS: UM CONVITE AO (RE)CONHECIMENTO DA REALIDADE RIBEIRINHA}

Nas discussões que interseccionam currículo e realidade social, torna-se essencial destacar alguns aspectos que compreendem a vida da comunidade ribeirinha. Assim, nesta seção serão apresentados, com base nas vivencias pedagógicas e pessoais do primeiro autor deste artigo, o contexto ribeirinho marajoara. A intenção é familiarizar os leitores com a realidade e possibilitar uma aproximação dos principais desafios enfrentados pelas famílias que residem nesta região.

O modelo socioeconômico desta região vem se transformado bastante, principalmente nas duas últimas décadas. A produção de açaí nativo, por exemplo, aumenta a cada ano. Isso proporcionou uma nova dinâmica no contexto ribeirinho. Muitas pessoas são atraídas para as regiões onde o cultivo é intenso. Diversas pessoas trabalham na colheita desse produto, outros para comercializarem seus derivados. Todavia, a extração e venda do açaí ocorre de maneira desordenada.

Para o caboclo-ribeirinho (expressão usada para se referir os moradores de comunidades ribeirinhas), o trabalho não é somente uma questão econômica, mas, sobretudo, um ato de relacionar-se com o ambiente e manter viva a cultura (OLIVEIRA, 2008). A autora supracitada destaca que, para o ribeirinho, "trabalhar é sentir-se vivo tanto quanto estar vivo é trabalhar" (OLIVEIRA 2008, p. 84). Similarmente, Corrêa (2006) afirma que "a vida cotidiana [no contexto ribeirinho] é o palco de construção destas relações onde se produz e se partilha significados" (CORRÊA, 2006, p.226).

$\mathrm{O}$ aspecto sociopolítico se manifesta de diversas formas, entre elas, as instituições que agregam os sujeitos ribeirinhos, como por exemplo, associações de pescadores, igrejas evangélicas e católicas, escolas, representações sindicais, partidos políticos, entre outras. Porém, 
há pouca participação dos ribeirinhos em alguns espaços, como por exemplo, escolas e sindicatos, o que configuram uma dificuldade, pois impede que muitos debates aconteçam no sentido de desconstruir as ideologias que inundam 0 contexto ribeirinho. Muitos sujeitos locais não se vêm capacitados para debater as questões sociais que os afligem.

O aspecto sociocultural é diversificado, sobretudo pelas relações que o ribeirinho estabelece com as águas e com a floresta. É bom destacar que todo modo de vida dessas populações é concebido a partir da grande influência da natureza. Quando se fala em cultura nessa região, não existe a possibilidade de descrevê-la sem fazer menção a esses elementos: o rio, a terra, a floresta e a lua. Toda relação de trabalho, transporte, alimentação e cura de doenças têm forte influência desses fatores. Lira e Chaves (2016) afirmam que o rio tem influência até na maneira como o ribeirinho constrói sua casa, o que significa dizer que "o rio possui um alto poder simbólico para ribeirinhos" (LIRA; CHAVES 2016, p. 8).

Há uma temporalidade própria para a comunidade ribeirinha marajoara. $O$ tempo de caçar ou de pescar é definido pela maré, pela floresta ou pela fase em que a lua se encontra. É importante destacar essa forma de se relacionar com o espaço local, pois esses aspectos influenciam as dinâmicas relacionais desta realidade. Lira e Chaves (2016, p.8) esclarecem que "as comunidades ribeirinhas se apropriam dos recursos florestais, baseado na reciprocidade com a natureza".

As contribuições de Oliveira (2008) e Abreu (2013) são significativas para a compreensão da importância do rio para o povo ribeirinho. "O rio é um elemento de diálogo com a natureza, cujo ribeirinho exerce também sua luta pela vida, utilizando-se de saberes e artimanhas" (ABREU, 2013, p. 100). O rio também "configura-se como uma representação simbólica e material no imaginário local" (OLIVEIRA, 2008, p.58). O barco é um instrumento significativo dentro dessa luta, como descrito por Abreu (2013), pois é com ele que o ribeirinho navega pelos rios e baías.

Dos rios nascem crenças, saberes, mitos e outras manifestações culturais. O rio é um espaço que ajuda o ribeirinho a construir sua história de lutas e conquistas. Para o povo das comunidades ribeirinhas, o rio é um palco democrático, onde todos, independentemente da etnia, pertencimento religioso, idade e gênero podem se manifestar e navegar pelas curvas e leito.

A terra é outro elemento emblemático para a vida do ribeirinho. Dela emanam saberes que influenciam no modo de vida. Abreu (2013) destaca que o trabalho com a terra que o ribeirinho realiza exige conhecimentos diversos, como por exemplo, o tempo para roçar, quando deve realizar o plantio e em que época irá começar a colheita. Esses conhecimentos vão sendo construídos no contato permanente que o caboclo-ribeirinho estabelece com o ambiente onde vive. Na verdade, ele, o caboclo-ribeirinho, é um grande observador da floresta, da terra, do rio e da lua. Oliveira (2008) afirma que todos os saberes e representações do imaginário popular têm relação com a terra e estão ligados à habitação.

A terra se constitui como um elemento que possibilita ao ribeirinho uma forma de viver peculiar e única. Dela nascem lendas, superstições e manifestações que consolidam o imaginário popular. "Assim como em relação à água e à mata, a terra inscreve-se no cenário ribeirinho como fonte imanente de alimento, de cura, de mistérios" (ABREU, 2013, p. 103). Similarmente, a floresta compreende uma fonte imanente de recursos. Dela são extraídos alimentos, madeira para a construção de casas e embarcações e ervas para curar doenças.

A lua também tem uma influência enorme sobre o modo de viver do ribeirinho. Ela interfere sobre o trabalho, a navegação, a caça e a pesca. Na verdade, a lua está tão presente na forma de viver do povo ribeirinho, que, muitas vezes, para mandar cortar o cabelo observa-se a fase em que a mesma se encontra. Diante desse contexto tão diverso, Almeida (2010) pontua: "o desafio é ensinar e aprender em um espaço no qual o rio e floresta são as bases da economia, da cultura e do lazer" (ALMEIDA, 2010, p. 23).

Todas as peculiaridades locais, sumariamente descritas nesta seção, muitas vezes são ignoradas pela escola para favorecer um conhecimento prescrito e sem função social. Ao reconhecer esses elementos históricos e sociais, fica evidenciada a necessidade da condução de pesquisas no campo educacional que estejam engajadas na compreensão de processos formativos de forma comprometida com esta realidade. 


\section{ESCOLA E EDUCAÇÃO RIBEIRINHA NA ILHA DO MARAJÓ (PA): PROBLEMATIZAÇÃO DE UMA REALIDADE}

A definição de escola e educação deve sempre estar ligada a dois aspectos: o tempo e espaço onde elas se estabeleceram. Por esta razão, acredita-se que a concepção de escola ribeirinha e educação ribeirinha devem obedecer à dinâmica de vida das pessoas que residem e dão vida a esses espaços.

$\mathrm{Na}$ seção anterior, foi apresentada ao leitor uma breve contextualização das dinâmicas sociais que permeiam a realidade ribeirinha. Parte-se agora, para uma descrição de uma realidade educacional, mais especificamente de escolas situadas no município de São Sebastião da Boa Vista. As discussões aqui empreendidas fazem parte do processo investigativo do primeiro autor deste ensaio, que realizou uma pesquisa de mestrado sobre o contexto educacional dessa realidade, além de ter atuado como docente e, atualmente, exerce a função de técnico educacional.

$O$ arquipélago do Marajó está situado no extremo norte do estado do Pará, na foz do rio Amazonas, sendo considerado o maior complexo de ilhas fluviais do mundo, com $49.606 \mathrm{~km}^{2}$, numa composição de 12 municípios (ALMEIDA, 2010). A localização da Ilha de Marajó, como já debatido, é elemento importante para a compreensão de três aspectos importantes: o socioeconômico, sociopolítico e o sociocultural. A região é conhecida por sua beleza natural, rios, igarapés, praias e campos.

A rede municipal é composta de 39 (trinta e nove) unidades de ensino, sendo 5 (cinco) na cidade e 34 (trinta e quatro) no interior. Essas unidades do contexto ribeirinho estão organizadas em três polos, como demonstra a tabela a seguir:

Tabela 1. Organização da educação ribeirinha em de São Sebastião da Boa Vista/Pará

Organização da educação ribeirinha em de São Sebastião da Boa Vista/Pará

\begin{tabular}{|c|c|}
\hline Polos & Unidades Escolares \\
\hline $\begin{array}{l}\text { Escola Polo Pedro } \\
\text { Nogueira }\end{array}$ & $\begin{array}{l}\text { Haidê Maia, Madre Oliveira, Mestre Justiniano, Custódio Ferreira, } \\
\text { Nazaré, São Marcos, Anacleto Castilho, Sítio do Pica-Pau Amarelo }\end{array}$ \\
\hline $\begin{array}{l}\text { Escola Polo Emmanoel S. } \\
\text { Lobato }\end{array}$ & $\begin{array}{c}\text { São Sebastião, Castanhal, Duque de Caxias, Vereador Engrácio, } \\
\text { Padre Silvério, Independência, Bambu, São Lucas, Maloca, São } \\
\text { Félix, Porto Alegre, Belos Prazeres, Lourival Camarão }\end{array}$ \\
\hline Escola Polo Caeté & $\begin{array}{c}\text { Expedicionário Mesquita, Cruzeiro, Caeté, São José, Menino Deus, } \\
\text { Rei Salomão, São Benedito, Alacid Nunes, Raimundo Pompeu, } \\
\text { Manoel Raimundo Pinheiro }\end{array}$ \\
\hline
\end{tabular}

Fonte: autores 2017

A organização por polos leva em consideração a geografia do município, sendo agrupadas por aproximação. A escola polo, por sua vez, é uma unidade que assume a gestão de um grupo de unidades de ensino e tem por finalidade organizar o planejamento anual, visitar periodicamente as escolas que integram o polo, fazer o acompanhamento pedagógico, acompanhar a matrícula dos alunos e organizar a documentação corresponde à vida do aluno. Desse modo, a escola polo acompanha as ações das demais, que ficam sob sua responsabilidade.

Periodicamente, o diretor do polo visita essas unidades para verificar o andamento dos trabalhos, bem como os problemas que precisam de solução. Se alguma situação carece de urgência em sua resolução, o diretor é quem intervém junto à Secretaria de Educação, no sentido de resolver as pendências. Assim, ele tem papel importante dentro da estrutura organizacional das escolas.

Essas entidades oferecem os seguintes níveis de ensino: educação infantil (pré-1e pré-2) e ensino fundamental (10 ao 9 o ano). No meio urbano, as atividades ocorrem em três turnos: manhã (das 07h30min até $11 \mathrm{~h} 30 \mathrm{~min}$ ), intermediário (das $11 \mathrm{~h}$ até $14 \mathrm{~h}$ ) e tarde (das $14 \mathrm{~h}$ às 18h). Já no meio rural, as turmas são organizadas em apenas dois turnos, no caso, manhã (07h30min às $11 \mathrm{~h} 30 \mathrm{~min})$ e tarde (13h às 17h).

No contexto ribeirinho do município, as atividades escolares acontecem obedecendo a uma lógica. Pela manhã, os responsáveis pelo 
transporte escolar, conhecidos regionalmente como "barqueiros", se deslocam pelos rios e vão embarcando as crianças ribeirinhas. Cada barqueiro transporta, em média, de 20 (vinte) a 30 (trinta) crianças, variando de 10 minutos a 2 horas o período de deslocamento de cada embarcação. Existem alunos que, devido à distância que moram, saem de suas residências antes das 06 horas e, isso, de acordo com o relato dos professores, gera um problema para a escola, pois as crianças ficam sonolentas durante as aulas. Caiado e Gonçalves (2014) também constataram que crianças que residem no meio rural sofrem para ter acesso à educação escolar.

Também existem situações em que as crianças, durante o período de estiagem (agosto a dezembro), caminham pela floresta para chegarem à escola. Nesse caso, o responsável pelo transporte escolar tem a responsabilidade de acompanhá-las durante todo o trajeto. Em síntese, destaca-se que muitas crianças enfrentam enormes dificuldades para permanecerem nas instituições educativas.

Os docentes que atuam nesse contexto são originários das comunidades locais. Isso deve ser considerado um fator positivo pela aproximação que há entre docentes e alunos. Outro fato significativo é que $90 \%$ dos professores já concluíram uma graduação e $5 \%$ está concursando o ensino superior (OLIVEIRA, 2016).

Essas características supramencionadas envolvem o modo de viver do ribeirinho local. É por essa e outras razões que Almeida (2010) declara ser um desafio trabalhar na educação na Ilha de Marajó, pois existem inúmeros desafios para efetivar uma proposta de educação que dialogue com todas essas peculiaridades. É preciso discutir questões importantes e que estão relacionadas aos fatores econômicos, políticos e sociais. Almeida (2010) afirma que se a escola ribeirinha dialogar com a sua comunidade e criar condição da participação efetiva de todos os seus membros, certamente esses entraves serão superados.

Existem problemas que têm dificultado o desenvolvimento de um processo de ensino e aprendizagem significativos para os sujeitos dessa região. Entre os entraves percebidos destacamse, por exemplo, crianças que trabalham coletando açaí para ajudar os pais na renda familiar. Essas crianças não se afastam definitivamente da escola, porém, a frequência e o rendimento escolar, na maioria das vezes, são baixos. Acredita-se que a integração efetiva entre família e escola seja um caminho na busca de superar essa situação. A esse respeito, Caetano (2009) destaca que quanto mais coesas escola e famílias, melhor a criança poderá desenvolver suas habilidades.

O estudo de Andrade e Reis (2018) apresenta informações relevantes sobre crianças ribeirinhas e o trabalho infantil em uma comunidade no interior da llha de Marajó. As autoras destacam que "as crianças dedicam algumas horas do dia para a realização de pequenas tarefas como colocar matapi, raspar mandioca para fazer farinha, apanhar açaí, pescar, caçar, vender peixe, pão, açaí, chope e salgados" (ANDRADE; REIS, 2018, p. 2). Portanto, as práticas educativas escolares devem levar em consideração o contexto de vida das famílias, que, em alguns casos, dependem dos seus filhos para o sustento. Levar isso em consideração poderia esclarecer porque algumas crianças demonstram cansaço ou baixo engajamento nas atividades educativas.

As autoras também salientam que existem mais situações que envolvem o cotidiano de crianças ribeirinhas, como por exemplo, exploração por aliciadores, o trabalho infantil e a prostituição infantil. Em outras palavras, essas crianças são expostas a diversas formas de violência e violação de direitos. Freire (2005) alerta que a educação deve ser problematizadora, pois, dessa forma, a escola se efetiva como instituição com papel importante para contribuir para a politização, humanização das pessoas e enfrentamentos dos problemas sociais que assolam a população. Todavia, se a escola não se envolver nas discussões inerentes ao cotidiano e as demandas locais, acaba por assumir uma postura acrítica e desvinculada dos problemas sociais. Entende-se que a proposta curricular escolar deve questionar como se tem produzido a infância no interior de São Sebastião da Boa Vista, bem como a função social das escolas no contexto das escolas ribeirinhas.

Poucas investigações científicas têm sido conduzidas neste local. Um trabalho recente, desenvolvido por Pires e Silva (2018), traz dados significativos sobre o contexto escolar. Segundo esses autores, os professores que atuam nas escolas ribeirinhas, muito bem-intencionados, buscam se valer do conhecimento vivido articulado às especificidades culturais das populações que vivem distantes dos grandes centros urbanos (PIRES; SILVA, 2018). Os autores 
relataram que os professores da escola pesquisada, com o objetivo de valorizar a cultura local, utilizaram o carimbó, que é uma importante expressão da identidade cultural paraense e elemento musical presente na vida das populações rurais e urbanas. O carimbó foi selecionado por caracterizar-se como uma herança sociocultural que mescla contribuições das culturas indígenas, ibéricas e africanas, ou seja, trata-se de uma experiência interessante e que se relaciona com a educação diferenciada (PIRES; SILVA, 2018).

Segundo Pires e Silva (2018), a utilização dessa expressão cultural marajoara foi interessante, pois possibilitou um leque de atividades que abrangeram várias áreas do conhecimento. Foi possível trabalhar geografia, a identidade cultural ribeirinha marajoara, o trabalho com a pesca, entre outros temas. Assim, os dados da pesquisa mencionados anteriormente robustecem a pergunta: por que as propostas curriculares anulam ou negligenciam as experiências cotidianas?

$\mathrm{Na}$ escola, é importante enfatizar conteúdos que sejam significativos, como por exemplo, uma prática pedagógica questionadora e um processo de educação diferenciada, pois, dessa forma, problematiza-se o contexto vivido pelos estudantes. Nesse sentido, defende-se que a escola ribeirinha deve se privilegiar novas formas do estudante se relacionar com 0 conhecimento, sempre no sentido de valorizar a identidade pessoal e coletiva. Daí a importância de uma proposta de currículo escolar que contemple o modo de vida do caboclo-ribeirinho.

\section{CURRÍCULO E EDUCAÇÃO RIBEIRINHA: ANÁLISE SOBRE (DES)ENCONTROS E DOMINAÇÃO IDEOLÓGICA}

Discutiram-se, até o presente momento, os desafios que a escola tem que enfrentar para efetivar uma proposta de educação comprometida com a dinâmica da realidade ribeirinha. Compreende-se que as discussões sobre a forma como o currículo escolar é praticado nesse contexto também precisam se intensificar para que a proposta curricular dialogue efetivamente com toda a forma de se relacionar do caboclo-ribeirinho com o espaço onde vive. Muitos estudos, como por exemplo, Hage (2005) e Abreu (2013), vêm contribuindo no sentido de aprofundar as análises sobre a educação escolar no contexto ribeirinho amazônico.
Os autores reconhecem que ocorreram algumas mudanças positivas, principalmente no sentido do acesso à escola, ampliação da rede escolar e qualificação no processo formativo dos docentes que atuam nesse contexto. Estudos como os de Abreu (2013), Almeida (2010), Ghendin e Borges (2007), Hage (2005), entre outros, contribuíram significativamente para ampliar os debates sobre a educação ribeirinha. Estas pesquisas deram grande destaque para uma temática que necessita ser revista e avaliada: o currículo escolar. Percebe-se um descompasso entre o currículo formal e o cotidiano das escolas que fazem parte deste contexto.

Além dos desafios que a própria geografia encarrega-se de apresentar, existe outros fatores que dificultam as atividades pedagógicas nessa região, entre elas, a falta de material didático adequado às demandas locais, uma vez que este ainda se fundamenta em realidades urbanas. Esta preocupação é apontada também na pesquisa de Abreu (2013), que destaca os livros didáticos no Brasil como "um currículo pensado no centro-sul do país".

Na mesma direção, o estudo de Almeida (2010) aponta dois problemas relacionados ao livro didático. Primeiro, o autor demonstra que há uma exclusão dos professores das escolas ribeirinhas do processo de escolha do livro didático. Segundo, os conteúdos abordados nos livros estão descontextualizados e não dialogam com a realidade local. $O$ autor argumenta que o "livro apresenta o conhecimento de forma disciplinar, descontextualizada e com viés ideológico" (ALMEIDA, 2010, p. 173). Esses entraves têm dificultado um processo de ensino e aprendizagem que valorize os saberes culturais das comunidades ribeirinhas.

Constata-se, portanto, a falta de diálogo do currículo escolar com as experiências sociais das comunidades ribeirinhas. Dib (2014, P.46) aponta que é importante "que a escola seja um reflexo das pessoas, do bairro, da comunidade que a forma". Todavia, percebe-se que tal apontamento não é levado em consideração na formulação das práticas pedagógicas no contexto ribeirinho.

Ao contrário, o que se evidencia é uma proposta de currículo sem função, que apenas está organizada para repassar conteúdo definidos arbitrariamente para a compreensão de outras realidades. Acredita-se que esse fator ocorre intencionalmente, no sentido de manipular a 
formação humana e transformá-la em instrumento de dominação, subjugando os sujeitos e transformando-os em meros espectadores. Santos Filho (2012) alerta que a sociedade manipula e domina o ser humano, impondo regras que têm como função escravizálo.

No contexto marajoara é evidente esse aspecto do currículo como instrumento alienador. As discussões curriculares são essencialmente conteudistas, além de inexistir espaços para fomentar debates críticos sobre a forma como a educação é gerida no espaço escolar ribeirinho. Há muitas formas de macular e operacionalizar um currículo que não compreende a cultura e o modo de vida do caboclo-ribeirinho. Isso se explica porque a proposta de educação ribeirinha em prática na atualidade é planejada por pessoas que vivem distante desse contexto, ocasionando uma desvinculação entre currículo e contexto social.

Por toda essa conjuntura, as escolas ribeirinhas, da forma como organiza suas práticas educativas, estão longe de cumprir o seu papel emancipatório. A partir da leitura de Mozzato (2003), percebe-se que a educação assume um caráter objetificante, transformando o estudante em aluno-objeto, sem poder de criação para compreensão de sua própria realidade e identidade cultural.

É necessário esse despertar para que docentes, pais, alunos, gestores e toda a comunidade percebam que 0 engajamento possibilita melhorias na educação. Tal como afirma Freire (2005), "quanto mais as massas populares desvelam a realidade objetiva e desafiadora sobre a qual elas devem incidir sua ação transformadora, tanto mais se "inserem" nela criticamente" (p. 44). Desse modo, para romper com essa lógica, é essencial que haja lutas consistentes, no sentido de transformar essa realidade educacional que não atende aos anseios das comunidades ribeirinhas.

A escola local precisa construir espaços de interlocução para rever conceitos, reavaliar conviç̧ões, superar dificuldades e contribuir para o aumento da consciência crítica de seus sujeitos. Deve partir do entendimento que, no campo curricular, "estão em jogo múltiplos elementos, implicados em relação de poder, compondo um campo privilegiado da política cultural" (COSTA, 2005 , p. 38). Enquanto não houver o entendimento que o currículo é o elemento orientador no processo de construção do conhecimento e na formação do sujeito, a escola ficará engessada dentro de uma proposta verticalizada e adestradora.

O desafio em romper com práticas que promovem uma educação que segrega o ser humano é incomensurável, pois foram elas que, historicamente, foram (e ainda são) praticadas no cotidiano das escolas, incluindo àquelas do contexto ribeirinho. O meio rural, por exemplo, antes visto como lugar pacato, onde residiam pessoas sem informação, mudou espantosamente. 0 caboclo-ribeirinho incorporou à sua vida novas maneiras de se vestir, de trabalhar, de ter lazer e, certamente, de se relacionar com o mundo. Sabe-se, contudo, que essas transformações não trouxeram somente benefícios, mas também, novas formas de exploração. A educação ribeirinha precisa atentar para essas questões que vão sendo impostas para a comunidade local, uma vez que a escola é um espaço privilegiado para problematizar essas questões.

Freire (2005) destaca que "somente quando os oprimidos descobrem nitidamente o opressor e se engajam na luta organizada por sua libertação, começam a crer em si mesmos" (p. 58). Acredita-se que esse descobrir-se como sujeito e a valorização da cultura local nas práticas escolares é um dos elementos necessários para o ribeirinho. Em outras palavras, somente por meio de uma educação libertadora e dialógica se conseguirá romper com o paradigma bancário de educação. No pensamento freiriano, encontram-se fundamentos de uma proposta educacional que busca a emancipação do homem. Segundo esse autor "o diálogo é esse encontro dos homens, mediatizados pelo mudo, para pronunciá-lo, não se esgotando, portanto, na relação eu-tu" (FREIRE, 2005, p. 91).

O diálogo, nesse sentido, é plural, é a voz de todos, especialmente das minorias e grupos historicamente excluídos. $\mathrm{O}$ contexto ribeirinho e as escolas carecem buscar essa ação dialógica que Freire (2005) discute com bastante densidade. Enfatiza-se a necessidade do currículo escolar dialogar com profundidade os aspectos culturais, econômicos e políticos do contexto ribeirinho. Isso implicará na valorização do modo de vida das comunidades locais e no inicio de processos emancipatórios dos mecanismos de exploração e adestramento impostos às famílias ribeirinhas. 
Nesse sentido, é essencial que a escola caminhe para conquistar sua autonomia, não apenas para administrar bens materiais, mas para discutir questões mais profundas, como a proposta curricular, por exemplo. Uma educação efetiva para as comunidades ribeirinhas deve propor que gestores, professores, pais, alunos e a comunidade em geral possam, conjuntamente, dialogar para que se construa uma proposta de educação de qualidade. Acredita-se que a construção do projeto político pedagógico seja o momento ideal para se construir essa proposta e pleitear uma prática pedagógica transformadora. Para conquistar a sua autonomia, a escola precisa envolver-se em ações inovadoras e audaciosas, pois o reflexo será, possivelmente, uma instituição participativa na vida social e que contribui para o desenvolvimento de sua comunidade. Abreu (2013) sugere que a escola atente para a diversidade cultural e o modo de vida do povo ribeirinho, sem excluí-los de sua proposta curricular.

Além disso, acredita-se que algo fundamental é uma mudança na cultura organizacional da escola. O diálogo que esse processo possibilita provoca inúmeras melhorias: o fazer pedagógico se transforma em prática que concebe o conhecimento empírico como elemento importante para a formação do sujeito e, ao mesmo tempo, o conhecimento científico é utilizado para o desenvolvimento da comunidade escolar.

Para que a escola avance no sentido de efetivar-se como uma instituição que tem um dever político e social, é preciso mudanças de atitude. Uma escola que não desperta para um processo de ressignificação e vive em práticas obsoletas, posterga a possibilidade de transformar-se em instituição que contribuiu para formação da consciência crítica dos atores envolvidos. Daí compreende-se que a escola deve fortalecer sua relação com a comunidade para que esta participe ativamente do seu cotidiano. A participação docente é outro fator crucial, pois ele é quem atua dentro da microestrutura escolar, a sala de aula. Sua participação nas tomadas de decisões é imprescindível, porque suas ações estão diretamente ligadas ao processo de ensino e aprendizagem. A escola ribeirinha precisa ser ativa e a cada dia caminhar potencializada por lutas, mas especialmente, por conquistas. Sugere-se, com isso, que seja dada especial atenção ao currículo que baliza a educação no contexto ribeirinho.

\section{CONSIDERAÇÕES FINAIS}

O currículo escolar é um campo de possibilidades múltiplas. Sua concepção deve fundamentar-se a partir das peculiaridades sociais que envolvem a escola. Todavia, o que se percebe é que a proposta curricular em prática nas escolas ribeirinhas não dialoga com as demandas dos povos locais. Entende-se que esse fator tem contribuído para a recorrência de problemas no espaço rural-ribeirinho das escolas ribeirinhas, pois o currículo expresso pela proposta de educação tem se distanciado das vivências locais, gerando um processo de ensino e aprendizagem com resultados que não satisfazem os anseios das comunidades locais.

A educação ainda é vista como uma prática assistencialista e ignoram-se todos os saberes que o caboclo-ribeirinho se apropriou a partir de suas experiências sociais. Os conhecimentos relacionados ao rio, a floresta e a terra passam despercebidos pela proposta curricular vigente. É necessário articular a vida desses povos com a prática educacional das escolas.

Este trabalho oportunizou uma reflexão sobre o currículo praticado nas escolas ribeirinhas. A pesquisa teórica realizada, bem como ações investigativas conduzidas e a inserção como educador nesta realidade, possibilitaram perceber a necessidade de ampliar os debates sobre a educação no contexto ribeirinho. O currículo tem representado a vontade de grupos hegemônicos que colocam a população ribeirinha em condição de subalternidade. O domínio que se estabelece através das propostas curriculares demonstra como as ideologias têm sido devastadoras para a população, sobretudo porque a educação escolar ganhou aspectos de uma ação opressora. Entende-se, apoiados em Freire (2005), que educação deve ser uma prática que conduz o ser humano para a liberdade, para a autocrítica, não para ser um mero reprodutor de ideias dominantes.

A proposta de educação ribeirinha precisa questionar alguns elementos que estão presentes no cotidiano do caboclo-ribeirinho, como por exemplo, o rio, a floresta, a lua e a terra. Estes são fatores fundamentais para a compreensão do processo histórico e ontológico das comunidades ribeirinhas amazônicas. Os conhecimentos proporcionados pela relação com esses elementos inexistem para o currículo escolar. 
O conhecimento é a transformação de tudo o que foi construído pelo povo para o seu próprio bem. Sem essa compreensão fica inviável construir uma proposta de educação que proporcione resultados que sejam relevantes culturalmente. Por esse motivo, se reafirma a importância de um currículo que se identifique com o contexto, com os anseios e as demandas sociais.

Portanto, o processo de ensino e aprendizagem no contexto ribeirinho só será diferente se houver o entendimento que a cultura e a história do povo são valores indissociáveis de sua vida. Não se conseguirá vencer as sequelas deixadas pela colonização ignorando as demandas e anseios atuais das comunidades ribeirinhas.

\section{REFERÊNCIAS}

ABREU, W. F. et al. (Org.) Educação ribeirinha: saberes, vivências e formação no campo. 2. ed. Belém: GEPEIF-UFPA, 2013.

\section{ALMEIDA,E. M. M. Educação Ribeirinha na}

Amazônia. São Leopoldo: Oikos, 2010.

ANDRADE, S. S.; REIS, M. Amazônia Marajoara: as crianças ribeirinhas e o trabalho infantil na vila do Piriá - Curralinho/pa. Revista labirinto issn 15196674 ano XVIII volume 28 (jan-jun) 2018 p. 15-27. Disponível em:

http://www.periodicos.unir.br/index.php/LABIRI NTO/article/view/3320

Acesso em: 25 nov. 2018

ARROYO, M. G. Currículo, território em disputa. Petrópolis, RJ: Vozes, 2011.

APPLE, M. W. Ideologia e currículo. 3. ed. Porto Alegre: Artemed, 2006.

CAIADO, K. R. M.; GONÇALVES T. G. G. L. O Transporte escolar público para os alunos do campo com necessidades educacionais especiais. Rev. Teoria e Prática da Educação, v.17, n. 1, p. 119-130, Jan./Abr. 2014.

Disponível em: http://ppeees.ufms.br/wpcontent/uploads/2016/02/transporte-escolarpublico.pdf Acesso em: 25 nov. 2018.

CORRÊA, P. S. A. (Org.). A Educação, o currículo e a formação de professores. Belém: EDUFPA, 2006.
COSTA, M. V. (Org.) O Currículo nos limiares do contemporâneo. 4. ed. Rio de Janeiro: DP\&A, 2005.

DIB, C. Caindo no Brasil: uma viagem pela diversidade da educação. São Paulo: Ed. do autor., 2014.

FREIRE, P. Pedagogia do oprimido. Rio de Janeiro: Paz e Terra, 2005.

GHEDIN, E.; BORGES, H. S. Educação do Campo: epistemologia de um horizonte de formação. Manaus: UEA, Edições, 2007.

HAGE, S. M. (Org.). Educação do campo na Amazônia: retratos de realidade das escolas multisseriadas no Pará. Belém: Gutemberg, 2005.

JESUS, A. R. Currículo e educação: conceito e questões no contexto educacional. 2008. Disponível em: http://lagarto.ufs.br/uploads/content attach/pat h/11339/curriculo e educacao 0.pdf Acesso em: 10 nov. 2016.

LIRA, T. M; CHAVES, M. P. S. R. Comunidades ribeirinhas na Amazônia: organização sociocultural e política. INTERAÇÕES, Campo Grande, MS, v. 17, n. 1, p. 66-76, jan./mar. 2016. Disponível em: http://www.scielo.br/pdf/inter/v17n1/15187012-inter-17-01-0066.pdf. Acesso em: 20 jan. 2017.

LOPES, A.; MACEDO, E. (org.) Políticas de currículo em múltiplos contextos. São Paulo: Cortez, 2006.

MACEDO, R. S. Currículo: campo, conceito e pesquisa. 4. ed. Petrópolis, RJ: Vozes, 2011.

MOZZATO, A. R. Para além do ensino técnico: educação dialógica-emancipatória. Passo Fundo, RS: Ed. Upf, 2003.

OLIVEIRA, I. A. (org.) Cartografias Ribeirinhas: saberes e representações sobre práticas sociais cotidianas de alfabetizandos amazônidas. 2. ed. Belém: EDUEPA, 2008. 
OLIVEIRA, I. B. (org.) Alternativas emancipatórias em currículo. 2.ed. São Paulo: Cortez, 2007.

(Série cultura, memória e currículo; v. 4).

OLIVEIRA, I. B. (org.) Currículo como criação cotidiana. Petrópolis, RJ: DP et alii; Rio de Janeiro: FAPERJ, 2012.

OLIVEIRA, F. M. S. Construção do projeto educativo escolar no contexto de uma Escola Ribeirinha Marajoara: desafios para uma ação participativa. (2014-2016). 2016. Dissertação (Mestrado em Educação) - Universidade do Oeste Paulista, Presidente Prudente, 2016.

PIRES, E. T.; SILVA, C. A. F. da. Práticas docentes em uma escola ribeirinha na ilha de Marajó (Pará, Brasil). Revista COCAR, Belém, V.12. N.23, p. 168 a 194 - Jan./Jun. 2018.

Disponível em:

https://paginas.uepa.br/seer/index.php/cocar/ar ticle/view/1723/94

Acesso em: 26 nov. 2108.

PONTUAL, P.; IRELAND,T. Educação popular na

América Latina: diálogos e perspectivas. Brasília: Ministério da Educação: UNESCO, 2009.

SANTOS FILHO, J. C. (org.). Projeto educativo escolar. Petrópolis, RJ: vozes, 2012.

SILVA, T. T. Uma introdução às teorias do currículo. Belo Horizonte: Autêntica, 1999.

Submetido em: 02/08/2018

Correções Obrigatórias: 07/11/2018

Aceite Final em: 09/12/2018 